\title{
The Value of Measuring Inspiratory Capacity in Subjects With Cystic Fibrosis
}

\author{
Daphna Vilozni PhD, Adi Dagan MD, Moran Lavie MD, Ifat Sarouk MD, \\ Bat-El Bar-Aluma MD, Moshe Ashkenazi MD, Sarina Levy Mendelovich MD, \\ Yael Betzalel MD, and Ori Efrati MD
}

\begin{abstract}
BACKGROUND: Inspiratory capacity (IC) is often overlooked as an important measured index of spirometry in patients with cystic fibrosis (CF). Abnormally low IC may indicate the onset of static/dynamic hyperinflation, which may be accompanied by dyspnea and an increase in the work of breathing. This cross-sectional study sought to determine whether measuring IC during spirometry, may add clinical value to $\mathrm{FEV}_{1}$ measurements in CF subjects. METHODS: Anthropometric, clinical, spirometry, and static lung volume data were gathered retrospectively from 98 of 165 subjects with CF (mean \pm SD age $26.8 \pm 11.0$ y) registered in The Edmond and Lily Safra Children's Hospital, Sheba Medical Centre, Israel. We compared the IC (\% predicted) to $\mathrm{FEV}_{1}$, static lung volumes, and hospitalization days/year. RESULTS: IC decreased alongside $\mathrm{FEV}_{1}$ decline but at a slower pace $\left(\mathrm{r}^{2}=0.32\right)$. Incremental trapped air, as measured by residual volume $(\mathrm{RV})$, and a rapid elevation in the ratio of $R V$ to total lung capacity occurred when IC deteriorated below $60 \%$ predicted values. The unique combination of IC $<50 \%$ predicted and $\mathrm{FEV}_{1}>\mathbf{4 0 \%}$ predicted induced an increase of up to 125 hospitalization days/year compared to subjects having IC $>50 \%$ predicted (up to $73 \mathrm{~d} / \mathrm{y}, P<.001$ ). CONCLUSIONS: Measuring IC in CF subjects may reveal silent worsening of lung function as indicated by a decline in IC $<50 \%$ predicted while $\mathrm{FEV}_{1}$ is still $>\mathbf{4 0 \%}$ predicted. This condition may lead to inefficient breathing at high lung volumes, which may explain a subjective sensation of breathlessness and lead to an increase in hospitalization days/year. Key words: spirometry; cystic fibrosis; lung function; lung volumes; FEV $V_{1}$ i trapped air. [Respir Care 2018;63(8):981-987. (C) 2018 Daedalus Enterprises]
\end{abstract}

\section{Introduction}

Cystic fibrosis (CF) is a life-shortening genetic disease that causes a thick build-up of mucus in patients' air-

The authors are affiliated with Pediatric Pulmonary Unit, The National Center for Cystic Fibrosis, The Edmond and Lily Safra Children's Hospital, Sheba Medical Center, Affiliated with the Sackler Faculty of Medicine, Tel-Aviv University, Israel.

This study was supported by the Gerald J Baum Fund. The authors have disclosed no other conflicts of interest.

Correspondence: Daphna Vilozni PhD, Pediatric Pulmonary Unit, The Edmond and Lily Safra Children's Hospital, Sheba Medical Center, Ramat Gan 52621, Israel. E-mail: daphna.vilozni@sheba.health.gov.il.

DOI: $10.4187 /$ respcare. 05920 ways. The mucus may partially or fully occlude the airways and can trap pathologic bacteria, leading to recurrent infections and inflammation, as well as the progression of damage to the airways due to lung disease. ${ }^{1,2}$ Lung function in $\mathrm{CF}$ is heterogeneous in severity, and the decline rate varies between patients. ${ }^{3}$

A milestone of lung disease progression follow-up in people with $\mathrm{CF}$ is the FVC maneuver, which should always performed according to global guidelines. ${ }^{4}$ In an FVC maneuver, the degree of airway obstruction is assessed either by $\mathrm{FEV}_{1}$, which for a long time was considered the most relevant predictor of mortality in $\mathrm{CF}$, or occasionally by the forced expiratory flow during the middle half of the FVC maneuver $\left(\mathrm{FEF}_{25-75 \%}\right) .{ }^{5}$ Conversely, grading lung function severity by a single measure in such a variable and complex disorder, raises the 


\section{MEASURING InSPIRATORY CAPACITY IN CF}

possible necessity of a multidimensional approach to lung function measurements in patients with CF. Indeed, other methods may assess pulmonary function deterioration in $\mathrm{CF}$, including the ratio of residual volume to total lung capacity (RV/TLC) or $\mathrm{FEF}_{25-75 \%} / \mathrm{FVC}$, ${ }^{6}$ which may be more sensitive than the $\mathrm{FEV}_{1}$ value.

While expiratory flows and volume are always measured and followed up, the inspiratory capacity (IC) is often overlooked. A reduction in IC may be noted by the presence of hyperinflation and trapped air. This phenomenon was previously found in subjects with COPD. ${ }^{7-10}$ Abnormally low IC and higher breathing frequency in patients with $\mathrm{CF}$ may indicate the onset of static/dynamic hyperinflation, leading to an increase in the work of breathing. This condition may also lead to worsening hypoxemia with varying degrees of hypercarbia and acidosis. ${ }^{11}$ It has been suggested that a decrease in IC may be accompanied by dyspnea due to breathing at high lung volumes (within anatomical dead space). IC may also be important in the presence of dynamic hyperinflation during exercise, ${ }^{12}$ in the evaluation of response to bronchodilators, ${ }^{13}$ and in the estimation of the operating volume that determines cough efficiency. ${ }^{14}$

$\mathrm{FEV}_{1}$ depends on the expiratory load on the airways, whereas IC depends on the inspiratory load, which includes the total resistive load, hyperinflation (position of the IC within the total lung), work of breathing, and muscular function. Thus, similar $\%$ of predicted values for $\mathrm{FEV}_{1}$ may not reflect the inspiratory load. The present study aimed to explore IC values in relation to the severity of $\mathrm{FEV}_{1}$ decline and to determine if IC may add value to the follow-up of lung function in subjects with CF.

\section{Subjects}

Patients with CF routinely visit the national Cystic Fibrosis Centre in The Edmond and Lily Safra Children's Hospital, at Sheba Medical Centre, Israel, affiliated with the Sackler Medical School at Tel-Aviv University. Data from 2004-2017 were collected from subjects with CF who were diagnosed according to consensuses and had similar gene mutation severity. Subjects varied with regard to the stage of lung-disease severity. Patients were excluded if pulmonary function tests did not meet European Community of Steel and Coal guidelines, or if lung function was measured during an exacerbation. Pulmonary function tests were performed using the Jaeger MasterScreen PFT system body plethysmography (CareFusion, San Diego, California), in the upright sitting position. The ethics committee of the Cystic Fibrosis Centre approved this retrospective, cross-sectional study (no. 1773-14-SMC).

\section{QUICK LOOK}

\section{Current knowledge}

The significance of measuring inspiratory capacity (IC) during forced spirometry in cystic fibrosis is vague. A reduction in IC may be noted in the presence of hyperinflation and trapped air, frequently accompanied by dyspnea due to breathing at high lung volumes.

\section{What this paper contributes to our knowledge}

Our study shows that a rapid increase in hospitalization days/year in CF subjects, with $\mathrm{FEV}_{1}$ above $40 \%$ predicted value, may be related to a combination of IC below $50 \%$ predicted value, and an increased residual volume. A simple forced spirometry and measurement of IC may therefore reveal sub-clinical worsening of lung function, allowing the opportunity for earlier intervention.

\section{Spirometry}

All spirometry measurements were performed according to American Thoracic Society/European Respiratory Society recommendations. ${ }^{15}$ Subjects were instructed to breathe normally, take the deepest breath possible, and blow as forcefully and as long as possible. Spirometry was performed routinely at each visit, and each subject visited our center every 1-3 months. We chose the best curve of the year according to annual best results of $\mathrm{FEV}_{1}+\mathrm{FVC}$ and IC data. Mean follow-up per person was $1 \mathrm{y}$. We compared the FVC, $\mathrm{FEV}_{1}$, and $\mathrm{FEF}_{25-75 \%}$ values to the Global Lung Function Initiative reference values, ${ }^{16}$ using the GAMLSS package via their site, ${ }^{17}$ to derive the best-fitting lung function index as a function of age and height in males and females.

\section{Plethysmography}

Body plethysmography data were collected from tests performed on the same day as spirometry was performed. Static lung volume was measured shortly after spirometry (ie, subjects were given a short resting period). Tests were carried out as recommended by the American Thoracic Society/European Respiratory Society. ${ }^{18,19}$ At least 3 functional residual capacity (FRC) measurements within a range of $5 \%$ were carried out to obtain reliable mean values. Lung-volume analysis included FRC, TLC, IC, and RV. The RV/TLC ratio was calculated. For comparison, we used the healthy reference values from the European Community of Steel and Coal mounted on the pulmonary plethysmograph, which included reference values for IC. ${ }^{20}$ 


\section{Measuring Inspiratory CAPACITY IN CF}

\section{Hospitalization Days/Year}

We considered subjects' hospitalization days only in relation to pulmonary exacerbations, where the clinical days were counted just for intravenous treatment. FEV and IC were collected during the visits to our laboratory between exacerbations throughout the year. Other reasons for hospitalization were not included.

\section{Statistical Analysis}

At the outset of data collection, there were 165 patients with CF registered in our clinic. We included 98 subjects who performed both plethysmography and full spirometry maneuvers. The analysis included data from 98/165 CF subjects in our clinic which reaches CI of 6.2. The power was $80 \%$. We believe that the sample size was sufficient.

Results are presented as mean \pm SD when normally distributed, or as median and $95 \%$ CI if the distribution was not normal (Mann-Whitney test). We used paired $t$ tests to compare the differences between measurements of the same patient, or unpaired $t$ test for differences between groups. Correlations between IC and $\mathrm{FEV}_{1}$ or other lung volumes or days of hospitalizations were sought using Pearson or Spearman correlation analysis. We used GraphPad InStat for the statistical analysis. $P<.05$ was considered significant.

\section{Results}

Data were available from 50 males and 48 females (mean \pm SD age $26.8 \pm 11.0 \mathrm{y}$, mean \pm SD body mass index $19.7 \pm 3.1 \mathrm{~kg} / \mathrm{m}^{2}$ with no significant difference between genders); 56 subjects (64\%) suffered from severe mutations (class I and class II having at least 1 severe mutation). The mean $\pm \mathrm{SD}$ of the spirometry indices and the static lung volumes are presented in Table 1. Mean $\pm \mathrm{SD}$ predicted values of $\mathrm{FVC}, \mathrm{FEV}_{1}$, and $\mathrm{FEF}_{25-75 \%}$ were moderately to severely reduced, but the SD was large. The mean $\pm \mathrm{SD}$ measured peak flow value was $5.8 \pm 2.1 \mathrm{~L} / \mathrm{s}$, where lower than the $2.2 \mathrm{~L} / \mathrm{s}$ needed for effective cough in 83 of the $98(85 \%)$ tested subjects.

\section{Inspiratory Capacity}

We found no significant differences between IC measured by the FVC maneuver and that measured by the slow vital capacity maneuver measured within the plethysmograph $(\mathrm{IC}=1.69 \pm 0.63 \mathrm{~L} / \mathrm{s}$ vs $1.70 \pm 0.64 \mathrm{~L}, P=.92$ respectively). The mean $\pm \mathrm{SD}$ measured IC value was reduced compared to normal $(65 \pm 20 \%, P<.001$ compared to healthy).
Table 1. Predicted Values of the FVC Maneuver and the Static Lung Volume

\begin{tabular}{|c|c|c|}
\hline Lung Function Parameter & \multicolumn{2}{|c|}{$\%$ of Predicted Value } \\
\hline $\mathrm{FVC}$ & \multicolumn{2}{|c|}{$66 \pm 20$} \\
\hline $\mathrm{FEV}_{1}$ & \multicolumn{2}{|c|}{$54 \pm 22$} \\
\hline $\mathrm{FEV}_{1} / \mathrm{FVC}$ & \multicolumn{2}{|c|}{$80 \pm 17$} \\
\hline $\mathrm{FEF}_{25-75 \%}$ & \multicolumn{2}{|c|}{$37 \pm 28$} \\
\hline $\mathrm{FEF}_{25-75 \%} / \mathrm{FVC}$ & \multicolumn{2}{|c|}{$54 \pm 32$} \\
\hline TLC & \multicolumn{2}{|c|}{$104 \pm 17$} \\
\hline $\mathrm{IC}$ & \multicolumn{2}{|c|}{$65 \pm 20$} \\
\hline RV & \multicolumn{2}{|c|}{$203 \pm 72$} \\
\hline FRC & \multicolumn{2}{|c|}{$137 \pm 33$} \\
\hline & $\%$ TLC & $\%$ of Predicted \\
\hline RV/TLC & $53 \pm 14$ & $197 \pm 54$ \\
\hline IC/TLC & $31 \pm 9$ & $64 \pm 18$ \\
\hline $\begin{array}{l}\text { All values are shown as mean } \pm \mathrm{S} \\
\mathrm{FEF}=\text { forced expiratory flow duri } \\
\mathrm{TLC}=\text { total lung capacity } \\
\mathrm{IC}=\text { inspiratory capacity } \\
\mathrm{RV}=\text { residual volume } \\
\mathrm{FRC}=\text { functional residual capacit }\end{array}$ & the middle $\mathrm{h}$ & \\
\hline
\end{tabular}

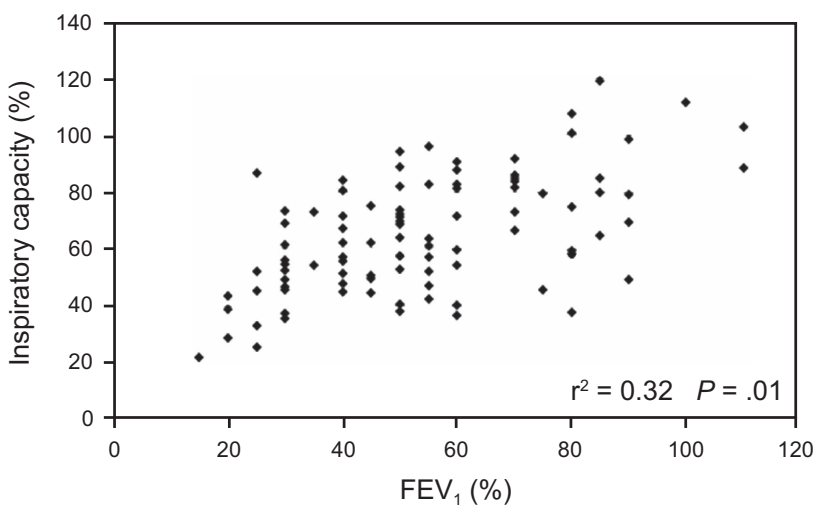

Fig. 1. Relationship between $\mathrm{FEV}_{1}$ and inspiratory capacity presented as $\%$ predicted values. GLI = Global Lung Function Initative.

The relationship between $\mathrm{FEV}_{1} \%$ predicted and IC $\%$ predicted is presented in Figure 1. Despite the significant correlation between $\mathrm{FEV}_{1} \%$ predicted decline and IC $\%$ predicted decline, low IC \% predicted levels may be found in subjects with mild $\mathrm{FEV}_{1} \%$ predicted obstruction $\left(\mathrm{r}^{2}=0.32, P=.01\right)$

\section{Other Static Lung Volumes}

A total of 77 subjects (79\%) had TLC values within the normal range. Among them, 43 subjects (57\%) showed trapped air, as indicated by increased RV $>200 \%$ predicted values, when $\mathrm{FEV}_{1}$ was $\leq 80 \%$ predicted values. Of the 15 subjects who displayed hyperinflation by higher 

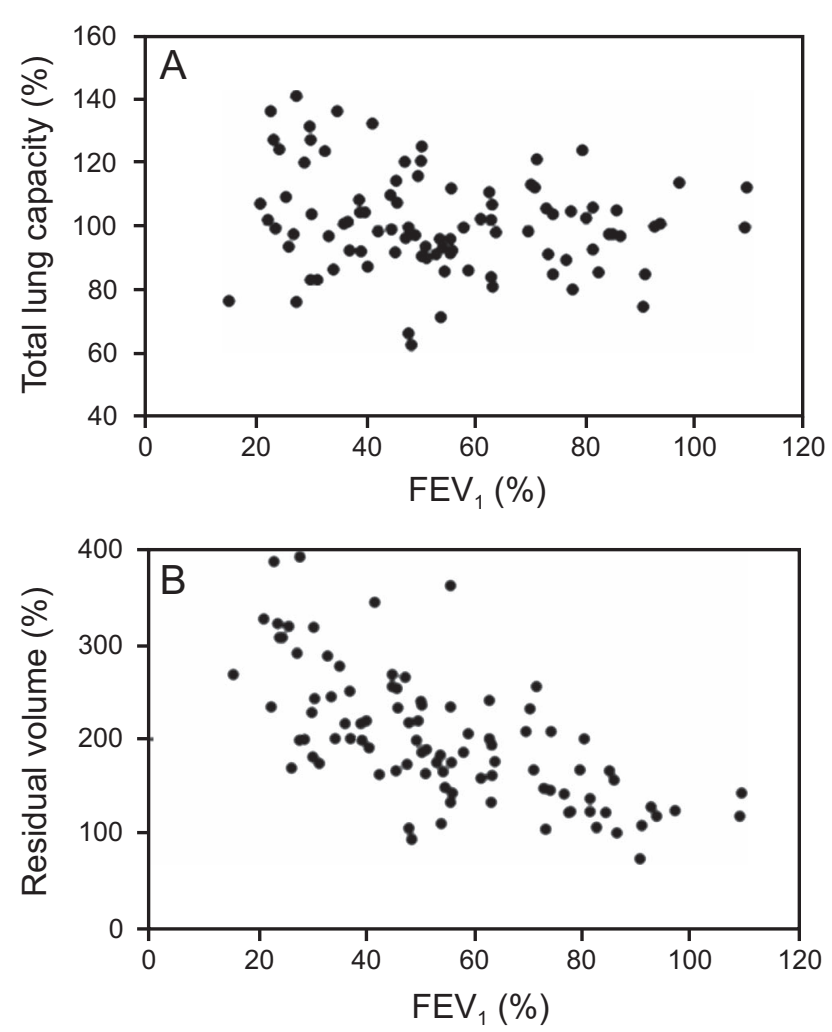

Fig. 2. Correlation between $\mathrm{FEV}_{1}$ and total lung capacity $(\mathrm{A})$ and $\mathrm{FEV}_{1}$ and residual volume (B) presented as $\%$ predicted values.

than normal TLC, $11(73 \%)$ had FRC $>200 \%$ of predicted values. FRC values $140 \%$ of predicted values were found when $\mathrm{FEV}_{1}$ was $60 \%$ predicted. A restrictive pattern was found in 6 subjects, indicated by TLC $\leq 80 \%$ predicted values. $\mathrm{RV}$ increased in relation to the decrease in $\mathrm{FEV}_{1}$.

While TLC \% predicted values did not correlate with $\mathrm{FEV}_{1} \%$ predicted values and remained within the normal range throughout the tested time period (Fig. 2A), there was significant correlation between the increase in $\mathrm{RV}$ values and $\mathrm{FEV}_{1}$ deterioration (Fig. 2B).

The relationships of IC/TLC and FRC/TLC to FEV $\%$ predicted values are presented in Figure 3. A marked reduction in IC/TLC was observed when $\mathrm{FEV}_{1}$ values reached $\leq 60 \%$ of predicted values. According to these correlations IC/TLC and FEV/TLC are equal when $\mathrm{FEV}_{1} \mathrm{FEV}_{1}$ is $67 \%$ of predicted values.

The relationship between IC and $\mathrm{FEV}_{1}$ (presented as $\%$ of predicted values) according to subgroups a- $d$ is presented in Figure 4. The subgroups included patients who had undergone lung transplantation; subjects listed for lung transplant are presented in red; subjects with $\mathrm{FEV}_{1}$ between 30-50\% predicted value combined with IC $<50 \%$ predicted (in green); other subjects had $\mathrm{FEV}_{1}>50 \%$ predicted values. Five of these subjects had low IC. The

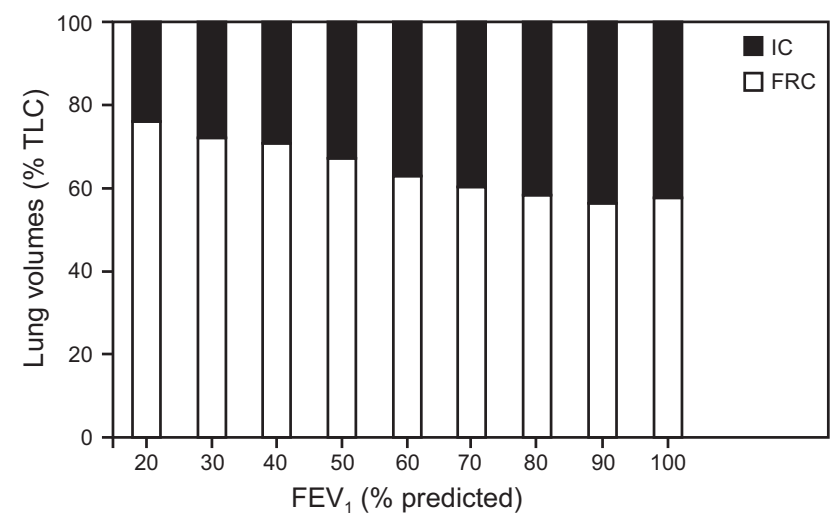

Fig. 3. Relationships of IC/TLC and FRC/TLC to $\mathrm{FEV}_{1} \%$ of predicted values. $I C=$ inspiratory capacity; $F R C=$ functional residual capacity; TLC = total lung capacity.

large circle stresses those patients with low IC at the variable $\mathrm{FEV}_{1}$ values.

The yearly days of hospitalization in relation to \% predicted values for IC are presented in Figure 5 according to the groups described in Figure 4. Subjects with IC $<50 \%$ predicted value had increased days of hospitalization despite having $\mathrm{FEV}_{1}$ values $>40 \%$ predicted value (median $56 \mathrm{~d}$ of hospitalization, range 7-125 d) compared to the subjects with IC $>50 \%$ predicted value (median $14 \mathrm{~d}$, range $0-73 \mathrm{~d}$, $P<.001)$.

\section{Discussion}

In this study we investigated whether measuring IC during the forced spirometry maneuver may add meaningful information concerning the severity and progression of lung disease in addition to the measurements of $\mathrm{FEV}_{1}$ in subjects with CF. Our study revealed that IC decreased with $\mathrm{FEV}_{1}$ decline, but at a slower pace. Consequently, subjects who manifested the combination of $\mathrm{FEV}_{1}>$ $40 \%$ predicted value and IC $<40 \%$ predicted value were occasionally listed for lung transplantation. However, subjects with a unique combination of IC $<50 \%$ predicted value and $\mathrm{FEV}_{1}>40 \%$ predicted value had increased hospitalization days/year compared to subjects with IC $>50 \%$ predicted value. Further, we found that the $\%$ predicted values of IC was in correlation with the elevation in residual volume.

Once IC values were $<60 \%$ predicted value, there was a rapid increase in FRC/TLC with a deterioration in IC/TLC, suggesting incrementally trapped air.

Imaging and pathology studies demonstrated that $\mathrm{CF}$ lung disease first develops in small peripheral airways, and those early changes can be restricted to local areas followed by more diffuse and severe involvement with concomitant closure of the airways while trapping the air. ${ }^{21-23}$ 


\section{MEASURING InSPIRATORY CAPACITY IN CF}

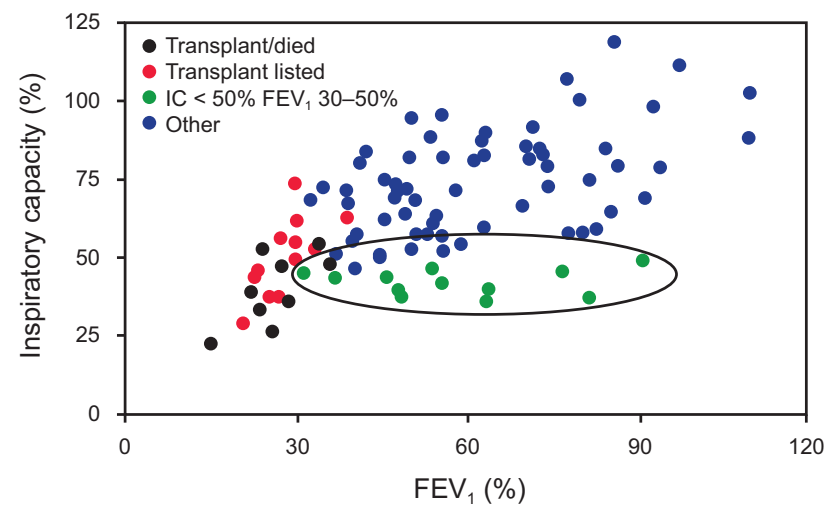

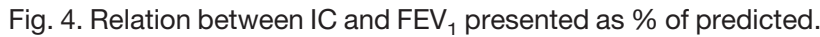
Subgroups include subjects who underwent lung transplantation, subjects who were listed for lung transplantation, subjects with $\mathrm{FEV}_{1} 30-50 \%$ predicted combined with IC $<50 \%$ predicted, other was defined as subjects $(n=64)$ with $\mathrm{FEV}_{1}>50 \%$ predicted. Five of these subjects had low IC. The circled area shows subjects with low IC across different $\mathrm{FEV}_{1}$ values.

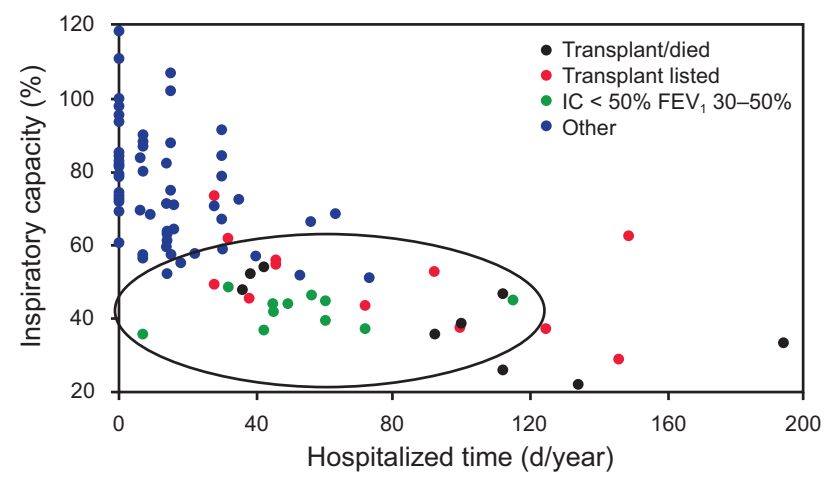

Fig. 5. Yearly time spent hospitalized in relation to inspiratory capacity (IC) \% predicted. The circled area shows subjects with IC $<50 \%$ predicted and $\mathrm{FEV}_{1}>30 \%$ predicted. $\mathrm{FEV}_{1}$ of $30 \%$ predicted serves as a hallmark for lung transplantation listing. Other was defined as subjects $(n=64)$ with $\mathrm{FEV}_{1}>50 \%$ predicted.

Consequently, small airways and parenchyma are the first to be involved and initially influence small airways $\left(\mathrm{FEF}_{25-75 \%}\right)$ value. IC reduction appears when trapped air is present. The appearance of different IC values at similar $\%$ predicted values of $\mathrm{FEV}_{1}$ may originate from enlarged and compliant central airways that may be present in subjects with $\mathrm{CF}$ as pulmonary disease progresses ${ }^{24}$ and artificially increases IC volume. Thus there might be an increase in airway dead space while the parenchyma is diffusely destroyed.

With pulmonary disease progression, static lung-volume relationships may be affected. We found that the reduction in IC levels best correlated with the increase in RV and less with FRC values. When RV (or FRC) elevation occurs, it leads to ventilation at higher lung volumes, which may improve flow through larger-diameter airways. Breathing at high FRC levels suggests a modification of the pressure/volume relationship. Yet, the pressure/volume curve is generally described as a sigmoid relationship in which the upper inflection point of the curve tends to flatten. ${ }^{25}$ Therefore, breathing at a high lung volume may cause a loss of aerated lung volume and dyspnea. ${ }^{26}$

RV, TLC, and FRC can only be measured by body plethysmography, or gas-dilution methods. Yet our study suggests that IC measured by spirometry may be meaningful, despite the fact that spirometry does not include these measurements. We found that IC deteriorates from normal values when $\mathrm{FEV}_{1}$ is $\sim 60 \%$ of predicted value. This is not the first study that strongly suggests that an $\mathrm{FEV}_{1}$ of $60 \%$ predicted value may be a turning point in the life of patients with $\mathrm{CF}^{27} \mathrm{~A}$ previous study showed that flow limitation at rest also occurs when $\mathrm{FEV}_{1}$ is $\sim 60 \%$ of predicted value. One of the consequences of having flow limitation at rest may be dynamic hyperinflation, ${ }^{28}$ which occurs when breathing requires a greater than normal inspiratory effort to offset threshold and elastic loads. ${ }^{29}$ Our findings of a decrease in \% predicted values of IC may therefore imply a slow process of dynamic hyperinflation indicated once $\mathrm{FEV}_{1}$ reaches $60 \%$ predicted value. Interestingly, we found that the deterioration in IC corresponds with an increasing number of yearly hospitalization days. This finding may also be connected with flow limitation at rest. ${ }^{27}$

Our study also showed a correlation between IC and $\mathrm{RV}$. Then again, inspecting abnormally low IC in patients with CF may indicate the onset of static/dynamic hyperinflation. Static/dynamic hyperinflation increases the work of breathing because patients have to breathe at higher FRC, as found in our study. This condition may lead to worsening hypoxemia with varying degrees of hypercarbia and acidosis. ${ }^{10}$

Four of our subjects who had very low IC values in combination with $\mathrm{FEV}_{1}>30 \%$ predicted value and frequent hospitalizations were assigned to lung transplantation. Taking into consideration that, for many years, $\mathrm{FEV}_{1}$ $30 \%$ predicted value was a hallmark for lung transplant consideration, ${ }^{5}$ our finding suggests that $\%$ predicted value of IC may add clinical value to $\mathrm{FEV}_{1}$ in the decision making regarding lung transplantation.

We found that the increase in the number of hospitalization days due to pulmonary exacerbations was related to IC $<50 \%$ predicted value. Commonly, an increase in breathing frequency and a decrease in saturation level may put the subjects in exacerbation state needing hospitalization. Our findings imply that the IC parameter should be added to the whole complex of factors considered in decisions concerning hospitalization or referral to lung transplant. ${ }^{30,31}$ 


\section{MEASURING InSPIRATORY CAPACITY IN CF}

Finally, we have formerly suggested that low \% predicted values of IC may indicate inefficient cough. The IC, which is also known as the operating volume, is known to reduce efficient secondary spike numbers during cough and may be helpful in the assessment of cough efficiency or assistance to a cough to remove mucus. ${ }^{12}$

\section{Study Limitation}

While this was a single-center study, the number of subjects included here is relatively large. Lung volume data obtained by plethysmograph in this study were not performed every year. Yet the distributions of lung volume results prior to and after having $\mathrm{FEV}_{1} 60 \%$ of predicted values has allowed the calculation of mean values with reasonable confidence of solid results. We could not measure the pressure/volume curve.

\section{Conclusions}

Measuring IC from the forced spirometry maneuver may add meaningful information concerning the severity and progression of lung disease in addition to $\mathrm{FEV}_{1}$ in subjects with CF. The combination of $\mathrm{FEV}_{1}<40 \%$ predicted value while IC $<40 \%$ predicted value may call for referral for lung transplantation, while the combination of having IC $<50 \%$ predicted value and $\mathrm{FEV}_{1}>40 \%$ correlated with an elevation in residual volume. These combinations suggest that subjects are breathing inefficiently at highlung volumes, which may explain dyspnea levels and the increase in hospitalization days/year, which are unexplained by $\mathrm{FEV}_{1}$ values alone. A prospective longitudinal follow-up in lung volumes may strengthen our findings.

\section{REFERENCES}

1. Kreda SM, Davis CW, Rose MC. CFTR, mucins, and mucus obstruction in cystic fibrosis. Cold Spring Harb Perspect Med 2012; 2(9):a009589.

2. Puchelle E1, Bajolet O, Abély M. Airway mucus in cystic fibrosis. Paediatr Respir Rev 2002;3(2):115-119.

3. Horsley A, Siddiqui S. Putting lung function and physiology into perspective: cystic fibrosis in adults. Respirology 2015;20(1):33-45.

4. Kerem E, Viviani L, Zolin A, MacNeill S, Hatziagorou E, Ellemunter $\mathrm{H}$, et al. ECFS Patient Registry Steering Group. Factors associated with FEV1 decline in cystic fibrosis: analysis of the ECFS patient registry. Eur Respir J 2014;43(1):125-33.

5. Kerem E, Reisman J, Corey M, Canny GJ, Levison H. Prediction of mortality in patients with cystic fibrosis. N Engl J Med 1992;326(18): 1187-1191.

6. Vilozni D, Lavie M, Ofek M, Sarouk I, Bar-Aluma BE, Dagan A, et al. Consequences of expiratory flow limitation at rest in subjects with cystic fibrosis. Ann Am Thorac Soc 2016;13(6):825-832.

7. Casanova C, Cote C, de Torres JP, Aguirre-Jaime A, Marin JM, Pinto-Plata V, Celli BR. Inspiratory-to-total lung capacity ratio predicts mortality in patients with chronic obstructive pulmonary disease. Am J Respir Crit Care Med 2005;171(6):591-597.

8. Tantucci C, Duguet A, Similowski T, Zelter M, Derenne JP, MilicEmili J. Effect of salbutamol on dynamic hyperinflation in chronic obstructive pulmonary disease patients. Eur Respir J 1998;12(4): 799-804.

9. O'Donnell DE. Breathlessness in patients with chronic airflow limitation. Mechanisms and management. Chest 1994;106(3):904-912.

10. Diaz O, Villafranca C, Ghezzo H, Borzone G, Leiva A, Milic-Emil $\mathrm{J}$, Lisboa C. Role of inspiratory capacity on exercise tolerance in COPD patients with and without expiratory flow limitation at rest. Eur Respir J 2000;16(2):269-275.

11. Reddy RM, Guntupalli KK. Review of ventilatory techniques to optimize mechanical ventilation in acute exacerbation of chronic obstructive pulmonary disease Int J Chron Obstruct Pulmon Dis 2007;2(4):441-452.

12. Calverley PMA. Dynamic hyperinflation: is it worth measuring. Proc Am Thoracic Soc 2006;3(3):239-244.

13. Boni E, Corda L, Franchini D, Chiroli P, Damiani GP, Pini L, et al. Volume effect and exertional dyspnoea after bronchodilator in patients with COPD with and without expiratory flow limitation at rest. Thorax 2002;57(6):528-532.

14. Vilozni D, Lavie M, Ofek M, Sarouk I, Efrati O. Cough characteristics and FVC maneuver in cystic fibrosis. Respir Care 2014;59(12): 1912-1917.

15. Miller MR, Hankinson J, Brusasco V, Burgos F, Casaburi R, Coates A, et al. ATS/ERS Task Force. Standardization of spirometry. Eur Respir J 2005;26(2):319-338.

16. Quanjer PH, Stanojevic S, Cole TJ, Baur X, Hall GL, Culver BH, et al. ERS Global Lung Function Initiative. Multi-ethnic reference values for spirometry for the 3-95-yr age range: the global lung function 2012 equations. Eur Respir J 2012;40(6): 1324-1343.

17. Cole TJ, Stanojevic S, Stocks J, Coates AL, Hankinson JL, Wade AM. Age- and size-related reference ranges: a case study of spirometry through childhood and adulthood. Statist Med 2009;28(5):880898.

18. Wanger J, Clausen JL, Coates A, Pedersen OF, Brusasco V, Burgos F, et al. Standardization of the measurement of lung volumes. Eur Respir J 2005;26(3):511-522.

19. Polgar G, Promadhat V. Pulmonary function testing in children: techniques and standards. Philadelphia, W. B. Saunders, 1971.

20. Quanjer PH, Tammeling GJ, Cotes JE, Pedersen OF, Peslin R, Yernault JC. Lung volumes and forced ventilatory flows. Report Working Party Standardization of Lung Function Tests, European Community for Steel and Coal. Official Statement of the European Respiratory Society. Eur Respir J 1993;6(Suppl 16):5-40.

21. Ries AL, Sosa G, Prewitt L, Friedman PJ, Harwood IR. Restricted pulmonary function in cystic fibrosis. Chest 1988;94(3):575-579.

22. Holland AE, Denehy L, Wilson JW. Does expiratory flow limitation predict chronic dyspnoea in adults with cystic fibrosis? Eur Respir J 2006;28(1):96-101.

23. Rosenthal M. Annual assessment spirometry, plethysmography, and gas transfer in cystic fibrosis: do they predict death or transplantation. Pediatr Pulmonol 2008;43(10):945-952.

24. Davis SD, Fordham LA, Brody AS, Noah TL, Retsch-Bogart GZ, Qaqish BF, et al. Computed tomography reflects lower airway inflammation and tracks changes in early cystic fibrosis. Am J Respir Crit Care Med 2007;175(9):943-950.

25. Ratjen F, Döring G. Cystic fibrosis. Lancet 2003;361(9358):681689.

26. Diwakar A, Adam RJ, Michalski AS, Tamegnon MM, Fischer AJ, Launspach JL, et al. Sonographic evidence of abnormal tracheal cartilage ring structure in cystic fibrosis. Laryngoscope 2015;125(10): 2398-2404.

27. Harris RS, Hess DR, Venegas JG. An objective analysis of the pressure-volume curve in the acute respiratory distress syndrome. Am J Respir Crit Care Med 2000;161(2 part 1):432-439. 


\section{MEASURING InSPIRATORY CAPACITY IN CF}

28. Brochard L. What is a pressure-volume curve? Crit Care 2006;10(4): 156.

29. Vilozni D, Lavie M, Ofek M, Sarouk I, Bar-Aluma BE, Dagan A, et al. Consequences of expiratory flow limitation at rest in subjects with cystic fibrosis. Ann Am Thorac Soc 2016;13(6):825832.
30. O'Donnell DE. Ventilatory limitations in chronic obstructive pulmonary disease. Med Sci Sports Exerc 2001;33(Suppl 7):S647S655.

31. Hirche TO, Knoop C, Hebestreit H, Shimmin D, Solé A, Elborn JS, et al. Practical guidelines: lung transplantation in patients with cystic fibrosis. Pulm Med 2014;2014:621342.

This article is approved for Continuing Respiratory Care Education credit. For information and to obtain your CRCE

(free to AARC members) visit

www.rcjournal.com 